УДК 94(4)

DOI 10.18413/2687-0967-2020-47-3-497-504

\title{
Дунайская граница Римской империи в «Res Gestae» Аммиана Марцеллина
}

\author{
Э.Е. Мейер \\ Российский государственный гуманитарный университет, \\ 125993, Россия, г. Москва, Миусская пл., д. 6 \\ E-mail: meyer_ed@mail.ru
}

\begin{abstract}
Аннотация. Методом дискурс-анализа «Res gestae» определены языковые практики, которыми Аммиан Марцеллин описывает Дунайскую границу Римской империи до и после переселения готов на территорию империи в 376 г. Изучение конкретных ситуаций, приведенных античным автором при описании готской войны, позволило ответить на вопрос - сохраняет ли Дунай после 376 г. статус границы империи в сознании позднеантичного историка. Выявлена двоякость видения реки в рамках изложенной Аммианом Марцеллином картины. Если определять статус реки через описываемые позднеантичным автором события, то граница Восточной Римской империи отодвинулась на юг и стала соотноситься с действующими частями армии, пытавшимися локализовать готское движение. Если же отталкиваться от лексики автора, то река сохраняет свой статус психологического рубежа, отделявшего римскую цивилизацию от варваров.
\end{abstract}

Ключевые слова: Римская империя, Дунайская граница, варвары, Аммиан Марцеллин.

Для цитирования: Мейер Э.Е. 2020. Дунайская граница Римской империи в «Res Gestae» Аммиана Марцеллина. Via in tempore. История. Политология, 47 (3): 497-504. DOI 10.18413/2687-0967-2020-47-3-497-504.

\section{The Danube frontier of the Roman empire in Ammianus Marcellinus' «Res Gestae»}

\author{
Eduard E. Meyer \\ Russian State University for the Humanities, \\ 6 Miusskaya Sq., Moscow, Russia \\ E-mail:meyer_ed@mail.ru
}

\begin{abstract}
In this article, the author applies the method of discourse analysis to «Res gestae» by Ammianus Marcellinus to characterize the language practices that describe the Danube border of the Roman Empire before and after the migration of the Goths to the imperial territory in 376. The study of specific situations given by the ancient author when describing the Gothic war allows to determine whether a late- historian considers the Danube as the imperial border after 376 . The ambiguity of the river's vision within the framework of the picture presented by Ammianus Marcellinus has been revealed. If to determine the status of the river through the events described by the late-antiquity author, the border of the Eastern Roman Empire had moved south and became related to the active parts of the army, that were trying to localize the Gothic movement. According to the Marcellinus's vocabulary, the river retains its status as a psychological frontier that separated Roman civilization from the barbarians.
\end{abstract}

Keywords: Roman Empire, Danube border, barbarians, Ammianus Marcellinus.

For citation: Meyer E.E. 2020. The Danube frontier of the Roman empire in Ammianus Marcellinus' «Res Gestae». Via in tempore. History and political science, 47 (3): 497-504 (in Russian). DOI 10.18413/2687-0967-2020-47-3-497-504. 
При изучении Готской войны 376-382 гг. и последующей за ней политикой Восточной Римской империи на дунайском направлении возникает вопрос о фактическом разграничении империи и варваров в условиях массовых переселений с целью определения статуса территорий. Интересно также и то, как жители империи видели происходившие события, как выражалось их восприятие в письменных источниках, как они реагировали на ситуацию в регионе во время развернувшихся военных действий.

Для ответа на эти вопросы необходимо изучение письменных свидетельств позднеантичных авторов, которые были более или менее знакомы с ситуацией на Балканах во время готского переселения. Одним из таких очевидцев войны был Аммиан Марцеллин (ок. 330 - ок. 395 гг.), солдат римской армии, вышедший в отставку после похода Юлиана Отступника в 360 г., грек по происхождению.

Его работа «Res gestae» была написана им по «горячим следам» войны на Балканах 376-378 гг. после его переезда в Рим в первой половине 390-х гг. [Ибатуллин, 2000, с. 9-10]. Она позволяет составить представление о событиях и территориях, на которых происходили эти события. Сам автор, скорее всего, лично, хотя и посещал будущий театр военных действий, но делал это до переселения готов (Amm. Marc. XXII. 8.1; XXVII. 4.2) [Barnes, 1998, p. 1-2]. В описаниях событий самого военного противостояния он ограничивался пересказом доступных ему материалов в риторической форме позднеантичной исторической традиции [Хизер, 2011, с. 229; 2016, с. 219]. Т. Барнс предположил, что Аммиан посещал Фракию в 377 г., где наблюдал останки погибших в битве при Маркианополе. Это утверждение основано на использовании Аммианом слова «теперь или сейчас» в описании места битвы (Amm. Marc. XXXI. 7.16): «Humatis denique pro locorum et temporis ratione honoratis quibusdam inter defunctos, reliqua peremptorum corpora dirae volucres consumpserunt adsuetae illo tempore cadaveribus pasci, ut indicant nunc usque albentes ossibus campi $^{36}$ ». Но, с другой стороны, только одного оборота недостаточно для однозначного вывода. Сведения, предоставленные Аммианом, содержат большее количество подробностей, чем у его современников - Евнапия и Иеронима Стридонского.

Предметом анализа в рамках настоящего исследования стали описания Марцеллином Придунайских территорий Восточной Римской империи. Его целью - анализ описания Дуная как рубежа в рамках «Res gestae» для ответа на вопросы:

- выступает ли река границей до и после готского вторжения?

- в какой момент наступает перелом в его понимании реки как линии разделения между римской цивилизацией и варварскими сообществами?

- какое место уделяет Аммиан Балканам в своей работе?

- сохранялся ли имперский контроль над регионом в условиях противостояния с готами?

Рассматривая историографию поднимаемых вопросов, стоит отметить, что сама граничная терминология, рассмотрение Дуная как границы и трансформации этого образа реки-рубежа в рамках описываемых событий не становились предметом самостоятельного исследования, как и сам римский лимес в указанный период.

К труду Аммиана так или иначе обращались все авторы, которые освещали вторжение готов на Балканы в 376 г. и последовавшее за ними разграбление Придунавья. Так, рассмотрение театров военных действий присутствует в статье Р. Зигера, который описывает политику императоров IV в. в этом направлении, а также на Рейне [Seager, 1999]. P. Зигер в центре своих изысканий располагает именно событийных ход, а не трактовки границ в «Деяниях», которым в его статье посвящено около трети от общего объема [Seager, 1999, p. 582-587, 592-604].

36 «Некоторые из павших, люди высших рангов, были преданы погребению, насколько позволяли это условия места и времени; хищные птицы, привыкшие в ту пору кормиться трупами, сожрали тела остальных, о чем свидетельствуют и до сих пор белеющие костями поля» (пер. Ю.А. Кулаковского). 
Свидетельства Аммиана в своих исследованиях готской истории и начального этапа переселения народов используют В.П. Буданова, А.А. Горский, И.Е. Ермолова [Буданова, 1990; Буданова, Горский, Ермолова, 2011], М.Б. Щукин, В. Вольфрам, П. Хизер, хотя эти авторы, так же, как и Р. Зигер, в первую очередь, концентрируются на самих событиях. П. Хизер все же, рассуждая об источниках, в которых описаны события, с которых начинается падение Римской империи, предположил, что Аммиан в своей работе, ввиду современности описываемых событий и даты завершения его труда, не мог до конца осознавать масштаб произошедшей войны и ее последствий [Хизер, 2011, с. 229; Хизер, 2016, c. 218]. М.Б. Щукин и В. Вольфрам использовали информацию, предоставленную Аммианом для составления карты готского вторжения и для установления пути готского переселения [Вольфрам, 2003; Щукин, 2005]. П. Хизер много места уделяет статусу переселяющихся и условиям, на которых готы были приняты [Хизер, 2011, с. 228, 254-257; 2016, c. 217-2019].

Специальное исследование труда Аммиана предпринял Т. Барнс, рассматривавший вопросы временных представлений автора, вкупе с анализом его биографии и источников вдохновения [Barnes, 1998]. Аналогичное исследование «Res gestae» посвятили И.Е. Ермолова [Ермолова, 2008] и А.В. Банников [Банников, 2015], а также Р.У. Ибатуллин в кандидатской диссертации [Ибатуллин, 2000]. Они рассматривали работу античного историка в рамках позднеантичной традиции историописания, указывая на терминологию и представления автора о труде историка, но вопросами дунайской границы они специально не занимались.

Дунайская граница, как и в общем весь Балканский регион, очень редко упоминается на страницах «Деяний». При исследовании граничной терминологии было установлено, что терминология границы как укрепленной линии - limes - в отношении реки не используется. Первое описание изучаемых территорий дается в XXVII книге. Дунайский регион описывается как край, где расположено множество городов, крепостей: «Partem vero sinistram arctois obnoxiam stellis Haemimontanae celsitudines claudunt et Hister, qua Romanum cespitem lambit, urbibus multis et castris contiguus et castellis ${ }^{37} \gg$ (Amm. Marc. XXVII. 4.6). При этом река является границей, что особо подчеркивается автором при помощи указания именно на берег как признак принадлежности. Далее Аммианом приводится история завоевания этих земель римлянами в древности (Amm. Marc. XXVII. 4.9-11) и географическая справка провинций, граница (confinus) с Иллириком, между Родопами и областью Европа (Amm. Marc. XXVII. 4.12-13).

Затем Придунайские территории появляются в работе в связи с походами Валента на готов 367-369 гг., так Валент зимовал в Маркианополе (Amm. Marc. XXVII. 5.5-6). Особое значение реки как рубежа вновь проявляется во время встречи Валента и Атанариха, которая мало того что проходила на реке, но и сам Атанарих данной клятвой утвердил ее особый политический статус как признаваемой обеими сторонами границы (Amm. Marc. XXVII. 5.9).

В следующий раз описания Придунавья появляются только в связи с войной 376-382 гг. (у Аммиана они описаны до 378 г.). В этих отрывках дается интересная информация об экономическом состоянии региона, например, говорится, что переселение готов во Фракию было спровоцировано высоким уровнем производительности местных пастбищ (Amm. Marc. XXXI. 3.8). Схожее описание территориям дает Евнапий (Eunap. Fr. 43).

Статус Дуная как границы при переселении никем не оспаривается. Аммиан явно дает понять, что наличествует система речного и берегового контроля за переселением (Amm. Marc. XXXI. 4.1-5; 4.9). Контроль за пересечением реки сохранялся и во время

37 «Левую сторону, обращенную к северным созвездиям, закрывают возвышенности Гемимонта и Истр, который на римском берегу течет мимо множества городов, крепостей и укреплений». 
второй волны переселения, в которой участвовали грейтунги, обошедшие речную оборону (Amm. Marc. XXXI. 5.3).

При изучении статуса Дуная как границы и фактического положения дел во время переселения необходимо рассмотреть условия, на которых были приняты варвары. Договор deditio, который должны были заключить с ними, предполагал почетную сдачу их на милость имперской администрации [Шувалов, 2006, с. 58-60; Хизер, 2011, с. 130-131, 254-256].

Одним из итогов заключения договора можно было бы считать введение части варваров в состав вспомогательной армии, которая должна была быть расквартирована в разных уголках империи (Amm. Marc. XXXI. 4.1-4.5; Eunap. Fr. 43, Jerome Ch. 380), в том числе и на Дунайской границе, однако однозначно сказать, был ли запущен процесс рекрутирования из переселенных, нельзя, так как о каком-то конкретном завершении переговоров между варварами и римлянами ни один автор не говорит. Иными словами, на момент поселения готов на территории римского берега Дуная императором Валентом и местными властями предполагалось полное и фактическое, и формальное сохранение существующей на территории Нижнего Дуная системы имперского управления, а значит, и контроля над границей.

Вероятно, именно неспособность быстрого распределения варваров по боевым частям стала причиной изначальной скученности варваров у реки и их хождения вдоль берега с римской стороны. Тервинги скитались вдоль берега в ожидании распределения и продовольствия (Amm. Marc. XXXI. 5.1). Люди Фритигерна, в свою очередь, выступили к стенам Маркианополя и ожидали там включения в состав римской вспомогательной армии (Amm. Marc. XXXI. 5.4). К скученности добавились проблемы со снабжением и антипатия местных римских властей (Amm. Marc. XXXI. 4.11; 5.1) [Буданова, 2011, с. 72; Хизер, 2011, с. 254256; Головина, 2017, с. 39-40]. Свою роль сыграла недооценка сил и возможностей противника с римской стороны [Ермолова, 2016, с. 58; Копаев, 2015, с. 212].

Ход дальнейшего противостояния хорошо описан в историографии и не требует повторного рассказа [Буданова, 1990; Heather, 1991; Хизер, 2001, с. 255-270; Вольфрам, 2003; Щукин, 2005; Буданова, Горский, Ермолова, 2011]. Однако интересным является то, что после поражения войск магистра Фракии Лупицина и отступления ромеев в регионе не осталось боеспособных отрядов полевой армии, что позволило готам расселиться по нему и дойти до Адрианополя (Amm. Marc. XXXI. 5.9; 6.5), что только углубило прорыв и увеличило неподконтрольную римлянам территорию. Более того, готы получили часть римского вооружения [Макдауэлл, 2011, с. 29].

Очевидно, единственной боевой единицей, способной исправить положение, стал федератский отряд Сферида и Колии, но и он не выступил из Адрианополя из-за задержки провианта (Amm. Marc. XXXI. 6.1-3). Тем самым, он не произвел никаких действий по возвращению контроля над берегом реки, а следовательно, по выведению границы к довоенному состоянию. Река все еще продолжает выступать у Аммиана границей, а переправа на римский берег сохраняет свое символическое значение, в тексте берег реки становится пристанищем готов после неудачной осады Адрианополя в 376 г. (Amm. Marc. XXXI. 6.5). В то же время, в результате начавшегося в регионе движения бедняков, неспособных платить высокие налоги вследствие разорения региона, рабочих рудников и жителей сельской местности против богатых и крупных хозяйств (Amm. Marc. XXXI. 6.5-6.), местные магистраты оказались неспособны исполнять свои властные полномочия, и нам не известна ни одна их акция против готов.

Неспособность имперских войск вернуть контроль над территориями и воздействовать на готов, наряду с неспособностью местных властей произвести то же самое, породили политический вакуум в регионе, где находились принятые готские племена. Территория, охваченная политическим вакуумом, росла по мере расползания готских групп в соседние провинции. Именно этим вакуумом и последующей ломкой существовавшей соци- 
ополитической системы объясняется восстание бедняков, которые начинали сопротивляться существующим налогам и воспринимали готов как альтернативную структуру военного управления, так как к моменту восстания бедняков договор deditio с готами был заключен, и они могли восприниматься как римские вспомогательные войска.

То, что во Фракии возник политический вакуум, а сама территория угрожала превратиться в буферную зону для следующих вторжений, прекрасно осознавалось римскими командующими, которые старались закрыть армиями выход варварам и восставшим беднякам за пределы провинции (Amm. Marc. XXXI. 7.1-2, 3, 5). В этих условиях интересен факт того, что речная оборона продолжала все это время существовать, судя по описаниям античного историка. Это проявляется в его апелляции к берегу Дуная, как одному из надежных рубежей нераспространения готского движения. В частности, доказательством этому служит отсутствие поставок через реку продовольствия и подкреплений для восставших варваров (Amm. Marc. XXXI. 8.1).

Утверждение Аммиана о нерушимости речной обороны, однако, опровергается описанием дальнейших событий. Так, несмотря на наличие определенной речной блокады, готы смогли отправить призыв к гуннам и аланам, соблазняя их добычей в случае успешного вторжения (Amm. Marc. XXXI. 8.3). Аналогичным отсутствием обороны по Дунаю можно объяснить появившийся на пути Фригерида, отступавшего в Иллирик, отряд тайфалов «transiere flumen» («перешедших реку»; Amm. Marc. XXXI. 9.3). На отряд аланов наткнулся Грациан, выступив из Сирмия в Кастра-Мартис (Amm. Marc. XXXI. 11.6). Вообще, про оборону реки в период до битвы при Адрианополе почти ничего не слышно.

Очевидно, что сложившееся положение не устраивало варваров, оказавшихся один на один с римскими укрепленными позициями и равнинами Фракии на протяжении реки до Родопы (Amm. Marc. XXXI. 8.6). Поэтому они пытались прорваться через Дибальту, но были отбиты Барцимером (Amm. Marc. XXXI. 8.9).

Еще два отряда были размещены в Сукках (Amm. Marc. XXXI. 10.20) и Мелантиаде (Amm. Marc. XXXI. 11.1). Причем второй находился на грани восстания из-за нарушения поставок, туда направился Валент для их успокоения (Amm. Marc. XXXI. 11.1, Eunap. Fr. 43).

Все это время река сохраняет у Аммиана статус рубежа, хотя в самой работе слово «граница» по отношению к реке перестает использоваться. О позиции автора можно судить косвенно, исходя из словесных оборотов, употребляемых в связи с переходом реки теми или иными племенами (Amm. Marc. XXXI. 9.2; 11.6). С другой стороны, события, описываемые античным автором, демонстрируют обратную ситуацию. Отступление римских войск к ущельям или большим пунктам, локальные восстания федератов вкупе с нехваткой продовольствия привели к тому, что граница на Дунае оказалась бесконтрольной, местные гарнизоны заняли опорные пункты и составляли собой островки римского влияния. Это понимали и готские вожди: накануне Адрианопольского сражения Фритигерн предложил Валенту передать готам Фракию с правом на весь урожай и продовольствие в провинции (Amm. Marc. XXXI. 12.8). П. Хизер рассматривает это предложение как свидетельство намерения готов не просто поселиться во Фракии, но и создать там полностью независимое от империи государственное образование готов [Heather, 1991, p. 176-177].

Ситуация после поражения римлян при Адрианополе усугубляется, так как на страницах текста упоминаются отряды гуннов, аланов и других варваров, прибывших «по горячим следам» на поддержку готам или пограбить римские земли (Amm. Marc. XXXI. 16.3-4). Это свидетельствует либо о прорыве обороны на реке, либо об отведении остатков местных полевых соединений в Иллирик, где стояли западные войска, с целью локализации варваров и произведенного ими прорыва границы в рамках регионов Мёзии и Фракии. Тем самым граница римского государства локализуется уже в местах расположения передовых отрядов полевой и гарнизонной армии вокруг территории прорыва по главным дорогам и опорным пунктам, т. е. войска расположились у Сирмия, КастраМартиса, Мелантиады, Сукк, Адрианополя. 
Любопытно, что аналогичное умалчивание относительно обороны и сохранения Дуная как рубежа присутствует и у Зосима, который придерживается последовательной позиции, согласно которой Дунай остался рубежом римского государства и после вторжения готов как официально, так и фактически. Доказательством этого стало наличие боеспособных римских войск на Дунае в 386 г. Аммиан описывает последовавшие позднее победы отрядов Промота, стремившегося пресечь дальнейшие переселения грейтунгов на римские земли (Zos. IV .35, 38-39), об этих событиях восторженно пишет и Клавдиан в панегирике на IV консульство Гонория (Claud. Cons. IV. v. 620-630). Эти победы произошли через десять лет после описанных Аммианом событий и могли выступить следствием возвращения территорий под римский контроль по результатам заключенного перемирия императора Феодосия с готами 382 г.

В результате анализа сведений работы Аммиана Марцеллина о Дунайском регионе и границе было установлено, что Дунай, будучи границей империи от завоевания его берега римлянами до готского переселения 376 г., формально продолжает восприниматься Аммианом как определенная линия разделения привычного римского мира и варварской периферии. Однако терминологического описания его как «границы» в работе нет. Полный прорыв Дунайского лимеса не был признан автором в полной мере, по крайней мере, на момент прихода в регион гунно-аланских и тайфальского отрядов, которые смогли беспрепятственно совершить переправу и вторжение на территорию Юго-Восточного Иллирика и Мезию I. Вопрос реки-рубежа уходит у Аммиана на второй план на фоне военных действий, т. е. вопрос границы государства сменился проблемой подконтрольности территории: провинции, оказавшиеся наводненными варварскими группами, как бы выпали из списка контролируемых земель, хотя и сохраняли анклавы римского управления в виде городов, которые не были взяты готами.

Таким образом, граница римского влияния фактически «откатилась» в сторону территории расположения римских военных отрядов, стремившихся локализировать прорыв в рамках ряда придунайских провинций, таких как Мёзия, Фракия. Свидетельством такого изменения стало формирование политического вакуума и последующих за ним движений бедноты, о которых говорит Аммиан. Иными словами, неспособность полевых армий обеспечить поддержку гарнизонам внутри пострадавших провинций и отсутствие свидетельств о действиях дунайских флотилий до 386 г. привело к потере фактического контроля империи над границей.

\section{Список литературы}

1. Банников А.В. 2015. Аммиан Марцеллин и особенности его исторического метода. Альманах современной науки и образования. Тамбов, Грамота. № 6: 19-25.

2. Буданова В.П. 1990. Готы в эпоху Великого переселения народов М., Наука, 233.

3. Буданова В.П., Горский А.А., Ермолова И.Е. 2011. Великое переселение народов. СПб., Алетейя, 337.

4. Вольфрам Х. 2003. Готы. Пер. с нем. Б.П. Миловидов, М.Ю. Некрасов, под ред. М.Б. Щукина, Н.А. Бондаренко и П.В. Шувалова. СПб., Ювента, 656.

5. Головина О.В. 2017. Германцы в ранней Византии. Дисс. канд. ист. наук. Белгород, 235.

6. Ермолова И.Е. 2008. Отношение Аммиана Марцеллина к труду историка: теория и практика. Вестник древней истории. № 4: 131-142.

7. Ермолова И.Е. 2016. Расселение варваров в Римской империи. Вестник РГГУ. Серия «Литературоведение. Языкознание. Культурология». (11): 56-64.

8. Ибатуллин Р.У. 2000. Аммиан Марцеллин: проблемы биографии в контексте эпохи. Автореф. дисс. канд. ист. наук. Казань: Изд. Казанского государственного университета, 15.

9. Копаев М.Ю. 2015. Везиготы на Дунае накануне и в начале Великого переселения народов. Дисс. канд. ист. наук. Воронеж, 275.

10. Макдауэлл С. 2011. Адрианополь 378 г. н. э. Разгром римских легионов. М., Эксмо, 96.

11. Хизер П. 2016. Великие завоевания варваров. М., Центрполиграф, 830. 
12. Хизер П. 2011. Падение Римской империи. М., АСТ, Астрель, 795.

13. Шувалов П.В. 2006. Секрет армии Юстиниана: восточноримская армия в 491-641 гг. СПб., Петербургское Востоковедение, 304.

14. Щукин М.Б. 2005. Готский путь (готы, Рим и черняховская культура). СПб., Филологический факультет СПбГУ, 576.

15. Ammiani Marcellini. 1999. Rerum Gestarum libri qui supersunt. Ed. by W Seyfarth. Ad. L. Jacob-Karau, I. Ulmann. Vol. 1-2. Teubner, Stuttgart, Leipzig.

16. Barnes T.D. 1998. Ammianus Marcellinus and the Representation of Historical Reality (Cornell Studies in Classical Philology). Ithaca, NY, Cornell University Press, 422.

17. Eunapius Sardianus. 1829. Fragmenta. Corpus scriptorium historiae Byantinae. Bonnae, Impersis ed. Weberi, 41-118.

18. Chronicorum libri duo. 1857. PG. T. XIX. Col. 99-598.

19. Claudianus. 1892. Panegyricus de Quarto Consulatu Honorii Augusti. Carmina. Ed. Th. Birt. Berolini, 678 (Monumenta Germaniae Historica, Auctores antiquissimi, vol. X).

20. Heather P. 1991. Goths and Romans 332-489. Oxford, Clarendon Press, 378.

21. Seager R. 1999. Roman Policy on the Rhine and the Danube in Ammianus. The Classical Quarterly, Vol. 49, No. 2. Cambridge University Press on behalf of The Classical Association: 579-605.

22. Zosimus. 1837. Historia nova. Corpus scriptorium historiae Byantinae. Bonnae, Impersis ed. Weberi, 455.

\section{Referenses}

1. Bannikov A.V. 2015. Ammian Marcellin i osobennosti ego istoricheskogo metoda [Ammianus Marcellinus and features of his historical method]. Al'manah sovremennoj nauki i obrazovanija [Almanac of modern science and education]. Tambov, Gramota. № 6: 19-25 (in Russian).

2. Budanova V.P. 1990. Goty v jepohu Velikogo pereselenija narodov [Goths in the Migration Period]. Moscow, Nauka, 233 (in Russian).

3. Budanova V.P., Gorsky A.A., Ermolova I.E. 2011. Velikoe pereselenie narodov [The Migration Period]. Saint Petersburg, Aletejja, 337 (in Russian).

4. Wolfram H. 2003. Goty. Saint Petersburg, Juventa. 656 (in Russian).

5. Golovina O.V. 2017. Germancy v rannej Vizantii [Germans in Early Byzantium]. Diss. kand. ist. nauk. Belgorod, 235 (in Russian).

6. Ermolova I.E. 2008. Otnoshenie Ammiana Marcellina k trudu istorika: teorija i praktika [The relation of Ammianus Marcellinus to the work of the historian: theory and practice]. Vestnik drevnej istorii [Journal of Ancient History]. № 4: 131-142 (in Russian).

7. Ermolova I. 2016. The Barbarian's settlements in the Roman Empire. RSUH/RGGU Bulletin: «Literary Teory. Linguistics. Cultural Studies», Series. (11): 56-64 (in Russian).

8. Ibatullin R.U. 2000. Ammian Marcellin: problemy biografii v kontekste jepohi [Ammianus Marcellinus: problems of biography in the context of an epoch] Avtoref. diss. kand. ist. nauk. Kazan', Izd. Kazanskogo gosudarstvennogo universiteta, 15 (in Russian).

9. Kopaev M.Ju. 2015. Vezigoty na Dunae nakanune i v nachale Velikogo pereselenija narodov [Visigoths on the Danube before and during the beginning of the Great migration]. Diss. kand. ist. nauk. Voronezh, 275 (in Russian).

10. Macdowall S. 2011. Adrianopol' 378 g. n. je. Razgrom rimskih legionov [Adrianople A. D. 378: The Goths crush Rome's legions]. M., Eksmo, 96 (in Russian).

11. Heather P. 2016. Velikie zavoevanija varvarov [Empires and Barbarians: Migration, Development and the Birth of Europe]. Moscow, Centrpoligraf, 830 (in Russian).

12. Heather P. 2011. Padenie Rimskoj imperii [The Fall of the Roman Empire: a New History of Rome and the Barbarians]. Moscow, AST, Astrel', 795 (in Russian).

13. Shuvalov P.V. 2006. Sekret armii Justiniana: vostochnorimskaja armija v 491-641 gg. [Secret of Justinian's army: army of Eastern Romans in 491-641]. Saint Petersburg, Peterburgskoe Vostokovedenie, 304 (in Russian).

14. Shhukin M.B. 2005. Gotskij put' (goty, Rim i chernjahovskaja kul'tura) [Gothic way (Goths, Rome and Chernyakhov culture)]. Saint Petersburg, Filologicheskij fakul'tet SPbGU, 576 (in Russian).

15. Ammiani Marcellini. 1999. Rerum Gestarum libri qui supersunt. Ed. by W Seyfarth. Ad. L. Jacob-Karau, I. Ulmann. Vol. 1-2. Teubner, Stuttgart, Leipzig. 
16. Barnes T.D. 1998. Ammianus Marcellinus and the Representation of Historical Reality (Cornell Studies in Classical Philology). Ithaca, NY, Cornell University Press, 422.

17. Eunapius Sardianus. 1829. Fragmenta. Corpus scriptorium historiae Byantinae. Bonnae, Impersis ed. Weberi, 41-118.

18. Chronicorum libri duo. 1857. PG. T. XIX. Col. 99-598.

19. Claudianus. 1892. Panegyricus de Quarto Consulatu Honorii Augusti. Carmina. Ed. Th. Birt. Berolini, 678 (Monumenta Germaniae Historica, Auctores antiquissimi, vol. X).

20. Heather P. 1991. Goths and Romans 332-489. Oxford, Clarendon Press, 378.

21. Seager R. 1999. Roman Policy on the Rhine and the Danube in Ammianus. The Classical Quarterly, Vol. 49, No. 2. Cambridge University Press on behalf of The Classical Association: 579-605.

22. Zosimus. 1837. Historia nova. Corpus scriptorium historiae Byantinae. Bonnae, Impersis ed. Weberi, 455.

\section{ИНФОРМАЦИЯ ОБ АВТОРЕ}

Мейер Эдуард Евгеньевич, аспирант кафедры Всеобщей истории Исторического факультета Российского государственного гуманитарного университета г. Москва, Россия

\section{INFORMATION ABOUT THE AUTHOR}

Eduard E. Meyer, postgraduate student, department of International History, Russian State University for the Humanities, Moscow, Russia 